\title{
PRÁTICAS DAS AÇÕES DE EXTENSÃO UNIVERSITÁRIA NA UFPA PARA SURDOS
}

\author{
Emanuelle Monteiro da Paixão ${ }^{1}$ \\ Francisca Maria Carvalho ${ }^{2}$
}

RESUMO: Este estudo objetiva verificar as contribuições da extensão universitária para a comunidade surda a partir das ações acadêmicas desenvolvidas na Universidade Federal do Pará (UFPA), onde foi realizado um mapeamento que abrangeu todos os câmpus da Universidade de forma online, considerando todos os projetos de extensão universitária (PEU) voltados à comunidade surda entre 2016 a 2021 nas bases eletrônicas de dados da PROEX. Assim, realizou-se uma análise documental e bibliográfica, utilizando os resumos e relatórios finais dos projetos. Os resultados mostram que foram encontrados em um total geral I.979 projetos de extensão e, após os critérios de inclusão e exclusão, foram selecionados 19 projetos de extensão voltados para a comunidade surda, distribuídos nos eixos temáticos: Educação, Saúde, Comunicação e Tecnologia e Produção. Conclui-se o quão importante é um projeto de extensão na área de educação de surdos para a sociedade acadêmica e externa, trazendo inúmeras possibilidades por meio de ações extensionistas para se alcançar a verdadeira inclusão a partir de conscientização, formação de qualidade para os futuros profissionais da área e, consequentemente, uma educação de qualidade para os surdos do Brasil.

Palavras-chave: Educação. Projeto de extensão. Surdos. Inclusão. UFPA.

\section{INTRODUÇÃO}

Este trabalho está vinculado ao Projeto de Extensão “Curso de Língua Portuguesa Para Surdos”, coordenado pela Profa. Dra. Francisca Maria Carvalho, aprovado no Edital PROEX No. oI/202I no âmbito do Programa Institucional de Bolsas de Extensão - PIBEX. Mas antes deste projeto, fui bolsista voluntária do Projeto de Extensão do Prof. Dr. Waldemar dos Santos Cardoso Junior, intitulado "Oficina de Leitura e Escrita de Português para surdos (OLEPS)”.

A participação nesses projetos possibilitou conhecer uma realidade que tinha acesso somente no campo teórico, porém somar essas duas realidades, teoria e prática foram um fator decisivo para o desenvolvimento como pessoa e futura profissional de Libras e de Língua portuguesa como segunda língua para surdos.

\footnotetext{
${ }^{1}$ Possui graduação em Letras Libras e Língua portuguesa como segunda língua para surdos pela Universidade Federal do Pará. Graduação em Ciências Biológicas pela Universidade Pitágoras Unopar. Atualmente ministra aulas de Língua portuguesa para surdos no Projeto de Extensão: PORTUGUÊS ACADÊMICO PARA SURDOS. E-mail: emanuellemonteirodapaixao@gmail.com.

${ }^{2}$ Doutorado em Letras pela Universidade Federal de Minas Gerais. Mestrado em Linguística pela Universidade Federal do Pará. Atualmente é professora Associado I da Universidade Federal do Pará. Faculdade de Letras. Instituto de Letras e Comunicação. Tem experiência na área de Linguística, subárea psicolinguística experimental, com ênfase no processamento prosódico de surdos.
} 
Partindo dessa experiência tão relevante, é possível afirmar a necessidade de que se desenvolvam mais projetos de extensão voltados para a educação de surdos. Tais projetos devem incentivar os professores e futuros professores a melhorarem a educação de surdos, bem como conscientizar as pessoas dessa problemática, desenvolvendo mais projetos de extensão para a melhoria das metodologias de ensino para surdos, para que assim possa chegar numa sociedade mais justa e igualitária.

Nesse panorama, há muitos estudos e pesquisas no meio acadêmico sobre o que se trataum projeto de extensão, entretanto pouco se investiga sobre os processos de elaboração de um. Questões sobre o direcionamento do público-alvo, sobre as discussões de ações, debates das ideias etc. são pouco tratados nos estudos acadêmicos. A percepção da escassez de estudos sobre essas questões é corroborada por Castro (2004):

\footnotetext{
A maioria dos trabalhos realizados enfoca o processo de construção histórica da extensão e sua inserção dentro da Universidade como uma terceira função. Porém, poucos são aqueles que investigam a prática dos projetos, seu dia a dia, sua influência no processo de formação dos discentes e sua contribuição para a consolidação de umcampo de conhecimento específico e das consequências dessas práticas acadêmicas. (Castro 2004, p. 02).
}

Diante disso, levantamos o seguinte questionamento: de que maneira a extensão universitária contribui para a comunidade surda? Acreditamos que as ações realizadas nos projetos de extensão contribuem para a inclusão da comunidade surda no mundo contemporâneo.

Buscando contribuir ao esclarecimento dessas questões, esta pesquisa tem como objetivo principal verificar as contribuições da extensão universitária para a comunidade surda. Especificamente, identificar as estratégias utilizadas pelos projetos de extensão da UniversidadeFederal do Pará na integração com a comunidade surda. Ademais, este estudo buscará analisar ações da extensão universitária para a comunidade surda nas seguintes temáticas: educação, saúde, comunicação, tecnologia e produção.

O presente trabalho está organizado em seis partes: a primeira parte é composta por esta introdução cujo objeto da pesquisa que tem como relevância as ações extensionistas da UFPA no contexto da educação de surdos. A segunda parte é composta pelo referencial teórico que traz um amplo embasamento para o texto. A terceira parte é composta pela metodologia da pesquisa, trazendo os meios pelo qual a pesquisa se desenvolveu. A quarta parte é composta pelos resultados e discussões, em que apresenta um apanhado de dados encontrados relacionados a interpretações. A quinta parte é 
composta pelas considerações finais, contendo

o tratamento de todos os processos mencionados na pesquisa sendo positivo ou negativo. Por fim, a sexta parte composta pelas referências às quais trouxeram as fontes primordiais para o desenvolvimento desta pesquisa.

\section{REFERENCIAL TEÓRICO}

O processo de desenvolvimento de uma sociedade se torna eficaz à medida que seus problemas tenham os apoios necessários. Dentre esses apoios está a educação, fundamental para sua evolução, que tem como um dos seus agentes, a Universidade. Essa instituição mantém um caminho em paralelo com a sociedade por meio de projetos de extensão visando à transformação de uma realidade. Essa realidade, majoritariamente, não atende às necessidades dos surdos, de forma que a educação deles passa despercebida. Não obstante, as ações da Universidade nessa questão evoluíram, mas ainda necessitam de mais transformações direcionadas para a extensão universitária, de forma que suas ações alcancem desde a formação competente de profissionais preparados para lidar com as situações mais complexas até à possível transformação que tanto se almeja na educação de surdos. Apoiando esse caminho, Chaves e Gamboa (2000) dizem:

Formar profissionais competentes para atuar em situações complexas, produzir conhecimento científico, elaborar materiais instrucionais para socializar conhecimentos, são desafios que nos propomos a encarar a partir do ensinopesquisa- extensão, tendo como princípio articulador o trabalho pedagógico (CHAVES; GAMBOA, 2000, p. 164).

As ações direcionadas à educação de surdos são complexas e desafiadoras e envolvem diretrizes que nortearão esse trajeto. Nogueira (2000) trata dessas diretrizes: "a formulação e a implementação das ações para a Extensão Universitária, devem ser subsidiadas por meio das seguintes diretrizes: INTERAÇÃO DIALÓGICA, INTERDISCIPLINARIDADE E INTERPROFISSIONALIDADE, INDISSOCIABILIDADE ENSINO-PESQUISA- EXTENSÃO, IMPACTO E TRANSFORMAÇÃO”.

Dessa forma, através da INTERAÇÃO DIALÓGICA se estabelece a troca de saberes entre Universidade e comunidade externa. Já a questão da INTERDISCIPLINARIDADE E INTERPROFICIONALIDADE requer a relação entre as ações do profissional e suas metodologias adequadas, materiais e conceitos que serão a base nesse processo. INDISSOCIABILIDADE ENSINO-PESQUISA-EXTENSÃO faz referência às ações 
da extensão universitária como formação de conhecimento e da pessoa como cidadã. No que se refere ao IMPACTO E TRANSFORMAÇÃO visa a unir Universidade aos problemas sociais, desenvolvendo ações como soluções capazes de transformar difíceis realidades.

A classificação das ações de extensão universitárias possui, dentre outras ações, o projeto de extensão denominado de:

\begin{abstract}
Ação processual e contínua de caráter educativo, social, cultural, científico ou tecnológico, com objetivo específico e prazo determinado. $O$ projeto pode ser: • Vinculado a um programa (forma preferencial - o projeto faz parte de uma nucleação de ações) - Não-vinculado a programa (projeto isolado). (Anexoı do arti.22, da Universidade Estadual do Rio Grande do Sul PROEX - Pró-Reitoria de Extensão, 2017).
\end{abstract}

São as ações citadas anteriormente que dão base fundamental à extensão enquanto projeto como um instrumento valioso de transformação social. Assim, o estudo e o desenvolvimento de um projeto de extensão voltados à educação de surdos encontra diversas realidades como: surdos que não sabem Libras; os que sabem Libras, mas não sabem ler, escrever e compreender o Português; os que se comunicam através de sinais caseiros, ou seja, sinais desenvolvidos em casa junto com a família etc. Diante disso, o projeto de extensão terá somente ganhos como resultado da ação, uma vez que pouco material se encontra para criar e avançar, sendo um verdadeiro desafio. Monteiro (2018) se atenta para esses desafios:

Quando a instituição se movimenta para eliminar barreiras e subsidiar democraticamente a acessibilidade a todos os estudantes, independentemente de suas diferenças, garante a oportunidade de participação com êxito nas atividades pedagógicas. Do contrário, será negado o direito sociolinguístico do outro e assim também desconsiderará suas potencialidades (MONTEIRO, 2018).

Dessa forma, a instituição reflete e age para alcançar uma sociedade igualitária e justa através de ações extencionistas que utilizam a educação para o desenvolvimento da comunidade surda, acreditando nas potencialidades e desenvolvimento dessas pessoas, garantindo o reconhecimento e o cumprimento de direitos dessa comunidade de forma digna.

Tratar da educação de surdos implica grandes desafios. Por exemplo, não há um manualpara o profissional seguir, pois é um trabalho que precisa ser vivenciado e pensado para criar, sob um novo olhar, estratégias, metodologias e materiais que sejam capazes de despertar o interesse em aprender e desenvolver potencialidades do aluno surdo. Nesse ínterim, a Universidade consegue estabelecer uma conexão diante dessa problemática adotando uma perspectiva das ações cujo projeto de extensão articula e manuseia de acordo 
com as necessidades de aprendizagem da comunidade surda. Assim, segundo López Melero (2012):

identifica três barreiras que dificultam ou impedem a participação dos sujeitos na construção do conhecimento e sua aprendizagem na instituição de ensino. Dentre as barreiras, a cultural (conceitual e atitudinal) e a didática (ensino-aprendizagem) são as que dificultam o maior desenvolvimento acadêmico" (MELERO, 2012, pag. 145)

Essas barreiras são difíceis de serem rompidas, porém é preciso que se estabeleça um compromisso profissionalmente e humanamente diante dos direitos a uma educação de qualidade atribuída a todos. Deve-se pensar em ensino-aprendizagem da pessoa surda como ponto primordial para sua evolução, para a vida, garantindo assim, sua autonomia e cidadania. A partir de ações geradas em projetos de extensão universitária voltados para a comunidade surda que se reflete no que falta ser feito, no que pode ser feito e no que pode dar certo através de pequenos resultados até se alcançar os objetivos. Assim sendo, a educação de surdos hoje é entendida e difundida como algo novo, esquecendo-se das lutas anteriores por uma educação digna e colocada em prática.

Colaborando essa ideia, Slomski (2010) destaca que a educação de surdos não pode ser vista como uma "novidade" e sim entendida como "a prática dos direitos humanos e da democratização da educação no âmbito da surdez”. Dessa forma, é primordial que se pense emeducação como uma prática que alcance a todos, sem exceção. Tal pensamento é uma das principais bases da Universidade substanciada na extensão, abrangendo também o ensino e pesquisa, que estão entrelaçados de maneira que garantam, por meio de suas ações, o direito de todos à educação, e promovendo conscientização sobre as necessidades do outro. Daí a grande importância de se desenvolver mais projetos de extensão voltados à educação de surdos.

\subsection{A Extensão Universitária e o Impacto Social}

A extensão universitária é o processo de desenvolvimento da produção das ações que serão implementadas através do projeto de extensão junto à sociedade para tentar sanar os problemas e dificuldades existentes. Dessa forma, “A Extensão Universitária é o processo educativo, cultural e científico que articula o Ensino e a Pesquisa de forma indissociável e viabiliza a relação transformadora entre Universidade e Sociedade”. (PLANO NACIONAL DEEXTENSÃO UNIVERSITÁRIA, 2000/200I).

Em consonância, o paralelo entre universidade e sociedade é o ônus que se torna 
possível e apresenta resultados satisfatórios e transformadores nas vidas por meio do projeto deextensão universitária, sendo uma tarefa difícil que envolve uma série de fatores para que de fato o projeto aconteça. Exemplos são o público-alvo, pessoas estimuladas a participar, espaços de apoio, materiais e segurança dos participantes (seguro de vida) etc. Todos esses fatores podem faltar e comprometer o resultado final de determinado projeto, logo quando o projetotem caráter online também enfrenta dificuldades muito frequentes como a falta de recursostecnológicos (computador, impressora e internet), primordiais para que o projeto se desenvolva. Partindo dessa premissa, um projeto de extensão precisa estar apto a enfrentar essas dificuldades e pronto a entrar em ação em prol de seu objetivo frente às necessidades da sociedade, trazendo uma gama de projetos e ações gerados para solucionar possíveis problemasexistentes na sociedade. Daí a relação entre comunidade universitária e sociedade com essas ações serem a base de estudo de um projeto de extensão, apontando como desencadear esse processo frente aos problemas e necessidades encontrados. Assim sendo, "Numa universidade, ambos os eixos devem estar respaldados na relevância da sua significação social, o quepode/deve ser intensificado por suas articulações com o âmbito da extensão" (ARROYO; ROCHA, 2oro, p. 136).

Por conseguinte, houve um período em que a universidade tinha caráter assistencial para com a sociedade externa, onde a sociedade participava apenas como ouvinte, sem interação, noentanto percebeu-se o quão grande poderia ser a extensão na vida das pessoas envolvidas quando pensada em suas possíveis ações juntamente com a sociedade. Referente a isso:

\footnotetext{
Do assistencialismo passou-se ao questionamento das ações desenvolvidas pela extensão; de função inerente à universidade, a extensão começou a ser percebida comoum processo que articula o ensino e a pesquisa, organizando e assessorando os movimentos sociais que estavam surgindo. (PLANO NACIONAL DE EXTENSÃO UNIVERSITÁRIA, 2000/200I).
}

Ao construir novos pensamentos, ideias e pesquisas envolvendo a extensão, o avanço da comunidade universitária e externa é perceptível, pois a partir do momento em que se traça metas, possibilidades e novas estratégias em união com os anseios da sociedade, tudo começa a melhorar e avançar para ambas as partes. Dessa maneira, a Universidade precisa estar em constante desenvolvimento de suas ações para continuar avançando em seus propósitos para com comunidade surda. Em contrapartida, esse grupo precisa continuar avançando por meio daeducação de qualidade, um direito inalienável deles. Consoante a isso: "Nesses movimentos a favor da educação de surdos que podem promover melhorias, 
transformações, mudanças nos espaços, é preciso trabalharmos juntos para um aconselhável tratamento e atendimento às suas necessidades, que são sujeitos iguais a todos os outros" (SKLIAR, 2013).

Um projeto de extensão tem forte impacto positivo na sociedade acadêmica e externa, quando a Universidade pensa em conjunto com a sociedade, os envolvidos desenvolvem ações que vão muito além de repassar conhecimento apreendido em pesquisas e estudos, é algo que humanamente desperta frente aos anseios da sociedade, de forma que:

A universidade não pode se imaginar proprietária de um saber pronto e acabado, que vai ser oferecido à sociedade, mas, ao contrário, exatamente porque participa dessa sociedade, a instituição deve estar sensível a seus problemas e apelos, quer através dos grupos sociais com os quais interage, quer através das questões que surgem de suas atividades próprias de ensino, pesquisa e extensão. " (PLANO NACIONAL DE EXTENSÃO UNIVERSITÁRIA, 2000/200I)

Trata-se da realidade da qual os acadêmicos envolvidos precisam estar atentos $e$ perceberem o que de fato acontece em meio ao processo de desenvolvimento do projeto de extensão, estando aptos às possíveis mudanças das ações de acordo com os novos problemas que forem surgindo ao longo do processo. Especificando assim:

Esse tipo de extensão - que vai além de sua compreensão tradicional de disseminação de conhecimentos (cursos, conferências, seminários), prestação de serviços (assistências, assessorias e consultorias) e difusão cultural (realização de eventos ou produtos artísticos e culturais) - já apontava para uma concepção de universidade emque a relação com a população passava a ser encarada como a oxigenação necessária à vida acadêmica. (PLANO NACIONAL DE ATUALIZADA, 2000/200I)

Tal oxigenação é necessária para o desenvolvimento de novos projetos pensados na inserção de pessoas surdas à sociedade como cidadãos autônomos, bons leitores capazes de reconhecer seu papel social, se tornem sujeitos críticos formadores de opinião e bons profissionais, mas que requer certo conhecimento de Libras e do Português para que desenvolva e aprimore a leitura do mundo que o cerca, sem muitas dificuldades. Além disso, são percepções que precisam ser abordadas e expostas para que todos compreendam a importância da educação de surdos ser pensada e articulada de forma que possamos ver avanço em suas vidas, superando as desigualdades. Assim, nivela-se:

Ao reafirmar o compromisso social da universidade como forma de inserção nas ações de promoção e garantia dos valores democráticos, de igualdade e desenvolvimento social, a extensão se coloca como prática acadêmica que objetiva interligar a universidade, em suas atividades de ensino e pesquisa, com as demandas da sociedade. (PLANO NACIONAL DE EXTENSÃO UNIVERSITÁRIA, 2000/200I).

Essas reflexões precisam ser feitas ao longo da vida acadêmica e também 
posteriormente a ela, pois são questões fundamentais desenvolvidas em projetos de extensão e pensadas sempre na ruptura das desigualdades e exclusão social, bem como no trabalho árduo e difícil, mas nunca impossível de alcançar.

\subsection{O surdo e seus direitos}

Cassiano (2017) em "O surdo e seus direitos: Os dispositivos da Lei 10.436 e do decreto 5.626" chama a atenção para a problemática o surdo e seus direitos da seguinte forma: Trata da educação formal do surdo mediante a lei que ampara esse processo, mostrando que nem sempre essas pessoas foram reconhecidas e amparadas por direitos e deveres, pois, foram conquistando seus direitos a partir de muitas lutas, tanto da comunidade surda quanto de educadores.

A obra é descritiva e utiliza principalmente da lei e decreto que reconhecem que o surdo tem direitos sobre uma educação formal e de qualidade, utilizando vários exemplos que, segundo o autor supracitado, demonstra que a lei respalda as pessoas surdas quanto a sua educação formal a partir da Libras com o objetivo de trabalhar a ideia do surdo e seus direitos. $\mathrm{Na}$ presente pesquisa, percebeu-se então que o autor se apoia em leis e decretos para levantar a hipótese de que com a aprovação da lei que garante o uso da Libras e a matrícula da criança surda em sala de aula comum, ambos seriam caminhos para a mudança nas condições dadas pela escola para a criança surda. Nesse sentido, cita, inclusive, os seguintes argumentos em: "As características da sociedade atual criam barreiras entre o mundo dos ouvintes e o mundo dos surdos. Mesmo com as leis que deixam claros os direitos do surdo, os preconceitos ainda são fortes na sociedade”. (CASSIANO, 2017, p. 03).

Esta resenha concorda com as ideias apresentadas devido às leis que reconhecem o surdo como cidadão de direitos e deveres. Contudo, sabemos que não é exatamente levado em consideração seus direitos, uma vez que percebemos a educação que os surdos recebem nas escolas comuns está baseada em uma falsa inclusão que utiliza o português como primeira língua tanto para ouvintes quanto para surdos, sem levar em consideração a Libras como primeira língua para surdos, bem como pelo fato do professor não saber Libras e não haver intérprete em sala de aula para amenizar esse descaso com a educação do surdo.

Por fim, a obra é rica em investigações e exemplos de como a sociedade se comporta perante o surdo, mesmo diante de leis e decretos que afirmem que são pessoas iguais a qualquer outra no que se refere aos direitos e deveres a serem cumpridos. Também, a obra é útil para 
entender o tema em questão, o que a título deste trabalho, torna-a relevante e atual para aprofundar os conhecimentos sobre o tema. Isso porque "O Surdo e seus Direitos: os Dispositivos da Lei 10.436 e do Decreto 5.626" é uma obra que pode ser indicada para professores, futuros professores, alunos e qualquer pessoa da sociedade por discorrer mais sobre as Leis, a educação de surdos, a Libras e seus direitos que precisam ser cumpridos e respeitados para que de fato a verdadeira inclusão e educação aconteçam, as quais sugerem conhecimentos interdisciplinares próprios para um entendimento mais fluído sobre o surdo e seus direitos.

\subsection{A cultura surda}

A cultura envolve o desenvolvimento da humanidade a partir de sua relação com as múltiplas formas pertencentes aos grupos humanos com variações de características próprias que os diferem uns dos outros e, ao mesmo tempo, os enriquecem, dando sentido à existência de cada grupo e de cada indivíduo. Nessa perspectiva, a cultura surda traz formas próprias que a caracterizam e a definem através de sua Língua (Libras), costumes, crenças, comportamentos e valores que precisam ser respeitados, assim como qualquer outra forma cultural. De acordo com Santos (2006. pág.7) "Por isso, ao discutirmos sobre cultura temos sempre em mente a humanidade em toda a sua riqueza e multiplicidade de formas de existência. São complexas asrealidades dos agrupamentos humanos e as características que os unem e diferenciam, e a cultura as expressa”.

Assim, não se pode falar em cultura surda sem falar em identidade surda, pois a identidade é formada dentro de uma perspectiva cultural por meio das relações sociais. Consequentemente, a identidade social surda tenta firmar seus valores em meio ao biculturalismo, no qual o surdo está imerso em dois grupos culturais: surdo e ouvinte, uma condição que de certa forma pode trazer benefícios ou atrapalhar o desenvolvimento de sua identidade cultural. Isso depende das atitudes de cada grupo, a forma com que se olha o outro, o respeito por suas características particulares e de sua cultura, sendo de suma importância para

o desenvolvimento pessoal e firmação de sua identidade cultural. Dessa forma, a aceitação de uma língua implica sempre a aceitação de uma cultura, conforme lembra Behares (1987). Assim, De Paula (2009):

A questão da língua de sinais, portanto, está inerentemente relacionada à cultura surda. Ou seja, ao se tratar da cultura surda como fator construtor da identidade surda, necessariamente trata-se da questão da língua de sinais-Libras. A cultura surda,por sua vez, remete à identidade do sujeito que convive, quase sempre, com 
as duas comunidades (surda e ouvinte). (DE PAULA, 2009, pág.412.)

Dessa forma, muito têm se falado em surdez, em cultura surda, mas pouco é feito para queas questões que a permeiam sejam de fato respeitadas, levando em consideração a Língua Brasileira de Sinais (LIBRAS) e, consequentemente a cultura por meio de uma educação de qualidade que valorize o ser humano como deve ser, que pode se dar por fatores como, a falta de conhecimento sobre o assunto e, com isso a falta de conscientização para a realização de práticas essenciais como uma educação que abranja a Libras e Português usando metodologias e estratégias que alcance tanto alunos ouvintes quanto surdos para o desenvolvimento eficaz, firmação e valorização da cultura surda.

\subsection{Educação bilíngue para surdos}

Educação bilíngue para surdos consiste no ensino e aprendizagem por meio da Libras e da Língua portuguesa em um contexto de sala de aula comum, porém há dificuldades na viabilidade dessa prática ao desenvolvimento do aluno surdo. Por exemplo, na maioria das salas de aula comum os ouvintes são majoritários e os surdos minoritários, isso torna a Língua portuguesa como primeira língua e a Libras como segunda língua, tornando as possibilidades de comunicação dos surdos mais escassos. Outra dificuldade encontrada regularmente são os professores que não sabem Libras e a falta de tradutores/intérpretes de Libras, os quais são fatores decisivos para o retrocesso do aluno surdo inserido em sala comum sem que seus direitos, cultura e a questão humana sejam respeitados. A partir disso, "São denominadas escolas ou classes de educação bilíngue aquelas em que a Libras e a modalidade escrita da Língua Portuguesa sejam línguas de instrução utilizadas no desenvolvimento de todo o processoeducativo”. (BRASIL, 2005, Artigo 22, §으.

Dessa forma, pensar em educação bilíngue para surdos é pensar em um contexto bilíngue, em que a escola seja um ambiente bilíngue, onde professores e alunos sejam bilíngues, que haja a inserção da Libras e Língua portuguesa, do contrário não se tem uma educação bilíngue de verdade. A partir disso que podemos perceber uma falsa inclusão, porém é preciso pensar em mudanças e agir corretamente para alcançar a tão sonhada escola bilíngue para surdos. Diante disso, Sá (2002, p. 65-66) lembra que "Incluir surdos em salas de aula regulares inviabiliza o desejo dos surdos de construir saberes, identidades e culturas a partir das duas línguas (a de sinais e a língua oficial de seu país) e impossibilita a consolidação linguística dos alunos surdos". 
A partir disso, percebe-se o retrocesso na educação de surdos quando inseridos em sala de aula comum sem qualquer interação entre professores e colegas de turma, uma vez que o surdo não sabe o Português e, muitas vezes a Libras, o ouvinte não sabe a Libras, o surdo se vê sem perspectiva de desenvolvimento no âmbito acadêmico e pessoal o levando a sérias consequências de estagnação na aprendizagem e problemas de aceitação quanto pessoa surda sem que seus direitos sejam respeitados, uma vez que, diante dessa triste realidade estão negligenciando vidas.

\section{METODOLOGIA DA PESQUISA}

Neste estudo utilizou-se o procedimento bibliográfico utilizando-se materiais já publicados e pesquisa documental que se vale de documentos pesquisados e elaborados para ter amplo acesso aos projetos de extensão aprovados pela Pró-Reitoria de Extensão (PROEX), pelo Programa Institucional de Bolsas de Extensão (PIBEX), no período de 2016 a 2021, e seus respectivos relatórios finais e as leis.

A busca pelos projetos de extensão foi feita pelo Sistema Informatizado de Assistência Estudantil (SISAE) na página de resultados, selecionando os projetos de extensão, em meio a outros programas, conforme o resultado final do PIBEX dos anos que se pretendia pesquisar. Visto que não se conhecia os nomes dos projetos, coordenadores, temáticas (esse último alvo da pesquisa), acionamos o filtro, o que não ajudou muito, no entanto, essa tarefa foi difícil, poisfoi necessário verificar todos os títulos dos projetos a fim de selecionar os de interesse do estudo.

Adotamos como critério de inclusão todos os projetos de extensão para a comunidade surda nos últimos seis anos e como critério de exclusão projetos que não abordavam ações para a comunidade surda por meio de leitura exploratória dos títulos dos projetos de extensão. Realizamos em seguida a leitura dos resumos dos projetos com o intuito de conhecer o que cadaprojeto pretendia alcançar e qual seu objetivo inicial. Portanto, demos continuidade ao processode buscas dos relatórios finais a fim de sabermos qual o resultado final e se realmente foi alcançado os objetivos esperados.

Para ter acesso aos relatórios, foi preciso criar um documento de anuência, ou seja, umofício que foi enviado via e-mail à PROEX e a alguns coordenadores dos projetos, sendo que $\mathrm{I}(\mathrm{um})$ coordenador ainda não havia finalizado o projeto, por isso não tinha um relatório final para colaborar com a pesquisa; e apenas I (um) coordenador colaborou com a pesquisa 
enviando seu relatório final e os demais coordenadores não deram um retorno. Destaca-se que a principio a análise seria realizada utilizando vários projetos e seus respectivos relatórios finais,no entanto, será com base no número de relatórios que recebemos.

A partir de todo o processo realizado, iniciamos as leituras interpretativas dos resumose relatórios finais dos projetos de extensão, buscando conhecer as contribuições dos projetos à comunidade surda, em busca de também conhecer as suas metas, se as desigualdades sociais na educação de surdos e barreiras de comunicação são realmente rompidas com a intervenção de

projetos de extensão e se, de fato, permite aos surdos meios eficazes para se tornar cidadãos autônomos preparados para a vida.

\section{RESULTADOS E DISCUSSÕES}

Neste artigo tencionamos verificar as contribuições da extensão universitária para a comunidade surda a partir do mapeamento dos projetos de extensão entre os anos de 2016 a 2021, evidenciando sua importância. Nesse sentido, foi possível verificar se há transformaçõesà medida que um projeto de extensão é desenvolvido junto à sociedade. Os estudos foram divididos por quantidade de projetos de extensão por ano de forma geral (Quadro or), quantidade de projetos de extensão por ano voltados a comunidade surda (Gráfico or), por eixo temático (Gráfico o2), análise entre resumo/objetivo e o resultado final de projeto de extensão (Quadro 02 ), por fim a síntese dos projetos de extensão (Quadro 03). Iniciando pela quantidade geral com o quadro or a seguir:

Quadro or - Quantidade de projetos de extensão por ano de forma geral

\begin{tabular}{|c|c|c|}
\hline ANO & $\begin{array}{c}\text { PROJETO DE EXTENSÃO } \\
\text { (GERAL) }\end{array}$ & $\begin{array}{c}\text { PROJETO DE EXTENSÃO } \\
\text { (COMUNIDADE SURDA) }\end{array}$ \\
\hline 2016 & 383 & 2 \\
\hline 2017 & 322 & 3 \\
\hline 2018 & $221+110$ & 4 \\
\hline 2019 & $28 \mathrm{r}$ & 4 \\
\hline 2020 & 236 & 3 \\
\hline 2021 & $206+220$ & TOTAL \\
& TOTAL GERAL & I9 \\
\hline
\end{tabular}

Fonte: A Autora (2021).

Nas buscas pelo ano de 2016 encontramos 383 projetos de extensão, sendo apenas 2 
projetos voltados para a comunidade surda; em 2017 foram encontrados 322, tendo somente 3 projetos para a comunidade surda; já no 2018 foram encontrados 221 projetos mais IIo de 2018/2, sendo 3 projetos voltados à comunidade surda. Em 2019 foram encontrados 28I projetos de extensão, dos quais eram 4 projetos voltados à comunidade surda; já em 2020 foram encontrados 236 projetos de extensão, sendo 4 voltados à comunidade surda e, finalmente, em202I foram encontrados 206 projetos de extensão mais 220 de 2021/2, em que 3 projetos eramvoltados à comunidade surda. No total, a partir desse processo de busca por projetos de extensão por todos os câmpus da Universidade Federal do Pará (UFPA) de forma online, foram encontrados em sua totalidade 1.979 projetos de extensão, dos quais i9 projetos de extensãoeram voltados para a comunidade surda.

Gráfico or - Quantidade de projetos de extensão por ano voltado à comunidade surda no período 2016-2021

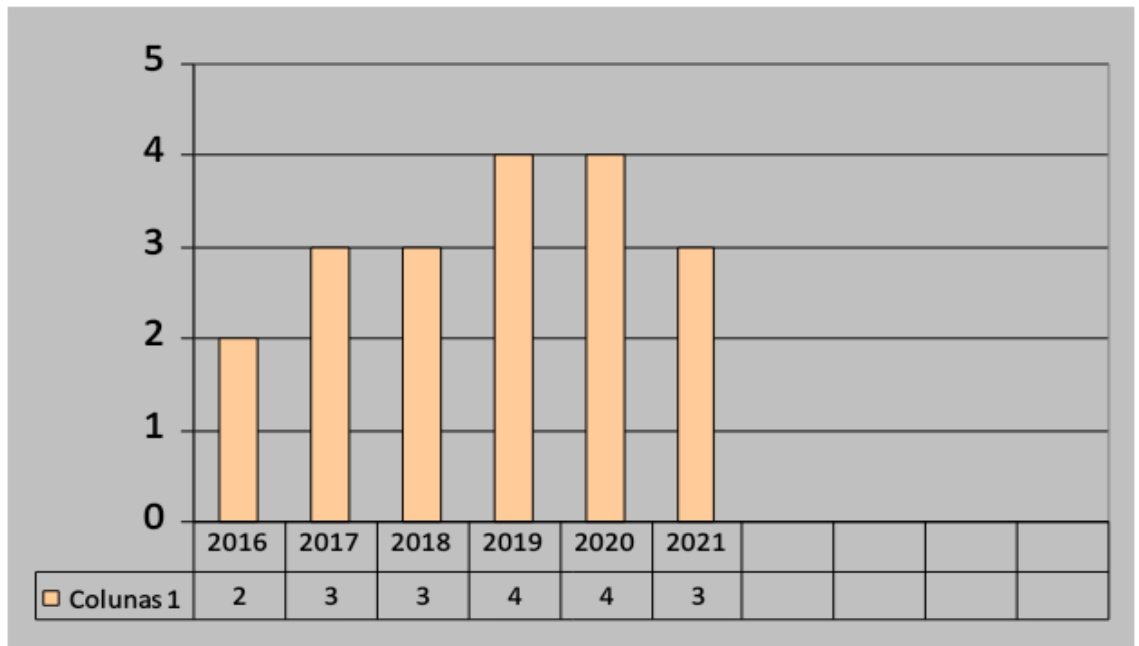

Fonte: A Autora (2021).

O gráfico or anterior expõe a quantidade de projetos de extensão voltados à comunidadesurda do intervalo de 2016 a 2021, em que se exemplifica por ano o número de projetos desenvolvidos. Destaca-se que em 2016 foram desenvolvidos 2 projetos de extensão, em 2017 foram 3 projetos, em 2018 foram 3, em 2019 foram 4 projetos, em 2020 foram 4 e em 2021 foram 3 projetos de extensão, totalizando 19 projetos de extensão. Evidenciando, portanto, queem 2016 houve um número menor de projetos desenvolvidos, já em 2019 e 2020 houve um crescimento nos números, enquanto em 2017, 2018 e 2021 permaneceram com os mesmos números. 
Gráfico 02-Quantidade de projetos de extensão voltados a comunidade surda por eixo temático

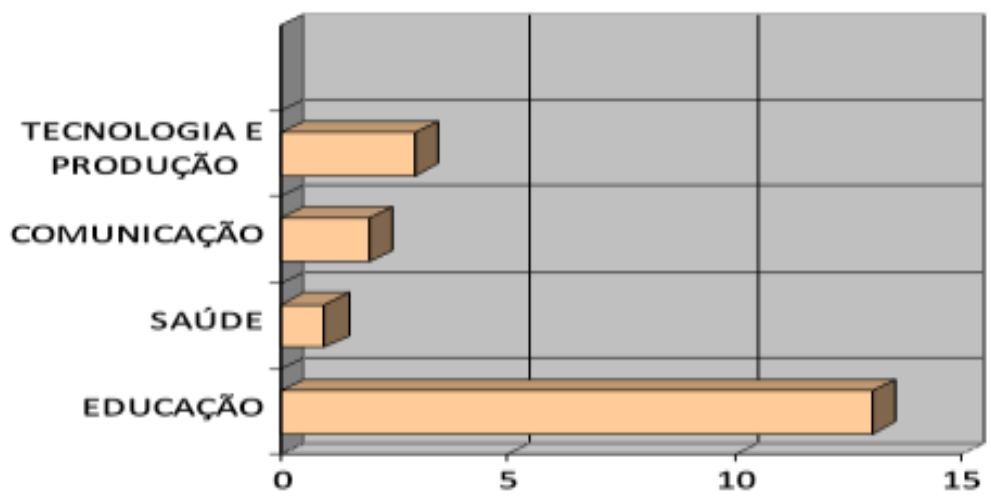

Fonte: A Autora (2021).

Analisados por eixos temáticos do gráfico 02, os projetos de extensão estão divididos em Tecnologia e Produção, Comunicação, Saúde e Educação. Assim, na temática Tecnologia e Produção foram desenvolvidos 3 projetos de extensão, sendo que nesta temática a abordagem é voltada para a questão das barreiras de comunicação que existe entre surdos e ouvintes. Gera- se a partir desses projetos ações relevantes para tentar romper essas barreiras, como a acessibilidade em Libras referente à UFPA, especificamente em seus espaços com sinalização e o incentivo ao ensino de Libras aos ouvintes. Inclui-se, também, a questão de geolocalização pelo público surdo de forma tecnológica nos espaços turísticos de Belém e questões de fortalecimento da comunicação entre surdos e ouvintes, estabelecendo um ambiente de aprendizagem e ensino de vocabulários da Língua portuguesa e seus significados.

$\mathrm{Na}$ temática da Comunicação foram desenvolvidos 2 projetos de extensão com o objetivo de difundir a Libras na Universidade por meio de um glossário digital com termos técnicos garantindo a melhor comunicação entre surdos e ouvintes de toda a comunidade universitária, especificamente entre alunos e professores do campus de Castanhal.

Já na temática da Saúde foi desenvolvido i projeto de extensão voltado para a comunidade surda, na área da Odontologia, visando a transpor a barreira de comunicação entre o paciente surdo e o profissional odontólogo com o uso de cartilhas e álbuns relacionados a Libras.

$\mathrm{Na}$ temática da Educação foram desenvolvidos 13 projetos de extensão, visando, em grande parte, ao ensino e aprendizagem da Língua portuguesa como segunda língua para 
surdose o ensino e aprendizagem de Libras para ouvintes. A frequência maior com que os projetos são desenvolvidos no campo da educação tem a ver com a questão de que todos têm direito à educação de qualidade para se desenvolver como cidadão autônomo. Por isso, com os surdos não seria diferente, uma vez que a eficácia de resultados em todos os projetos em outras temáticas depende da aprendizagem deles, ou seja, que os surdos saibam ler, compreender e escrever o Português, e não saber somente a Libras. Entretanto, os surdos podem conhecer os sinais referentes à imagem ou uma palavra em Português, mas talvez não saibam seu significado. Desse modo, frente às questões de desigualdade como essa tem o fator Educação, o qual segundo muitos estudos mostram que não está sendo adequada e eficaz aos surdos. Em virtude disso, é de grande importância que se desenvolva mais projetos de extensão voltados à educação de surdos, visto que esta pesquisa demonstrou que I9 projetos de extensão, divididospor ano e eixo temático ainda são poucos para essa área.

Quadro o2 - Análise entre resumo/objetivo e relatório final de projeto de extensão

\begin{tabular}{|c|c|}
\hline RESUMO/OBJETIVO & RESULTADO FINAL \\
\hline $\begin{array}{c}\text { OFICINA DE LEITURA E ESCRITA DE } \\
\text { PORTUGUÊS PARA SURDOS (OLEPS) } \\
\text { WALDEMAR DOS SANTOS } \\
\text { CARDOSOJUNIOR } \\
\text { ESPERA-SE COM A EXTENSÃO } \\
\text { UNIVERSITÁRIA OFICINA DE LEITURA } \\
\text { DE ESCRITA DE PORTUGUES PARA } \\
\text { SURDOS (OLEPS) PROMOVER A } \\
\text { INTEGRAÇÃO ENTRE ENSINO? } \\
\text { PESQUISA? EXTENSÃO A CONTRIBUIR } \\
\text { COM A MELHORIA DA QUALIDADE DO } \\
\text { ENSINO, DO RENDIMENTODA } \\
\text { APRENDIZAGEM DOS DISCENTES, DA } \\
\text { ATUALIZAÇÃO DO CONHECIMENTO } \\
\text { DO CURSO DE LICENCIATURA EM } \\
\text { LETRAS? } \\
\text { LIBRAS E LÍNGUA PORTUGUESA } \\
\text { COMOSEGUNDA LÍNGUA PARA } \\
\text { SURDOS. }\end{array}$ & $\begin{array}{l}\text { As metodologias que foram e que estão sendo } \\
\text { utilizadas com os alunos surdos, e refleti sobre os } \\
\text { resultados das práticas dessas metodologias de } \\
\text { ensino de Língua Portuguesa para surdos, usando } \\
\text { a Língua Brasileira de Sinais - Libras no PEU- } \\
\text { OLEPS foi lá que tive a oportunidade de ampliar } \\
\text { essas reflexões de como ensinar os surdos a ler e } \\
\text { escrever, como forma de iniciar minha prática } \\
\text { docente. Aqui experimentei o processo de } \\
\text { elaboração de aulas dentro da abordagem } \\
\text { interacionista para o ensino da Língua } \\
\text { Portuguesa em sua modalidade escrita, e percebi } \\
\text { a necessidade urgente de professores de Língua } \\
\text { Portuguesa com domínio em Libras nas } \\
\text { instituições de ensino. Esta constatação me } \\
\text { motiva ainda mais a continuar o } \\
\text { aprofundamento dos estudos, bem como a } \\
\text { produzir mais materiais para que sejam } \\
\text { ferramentas dentro desse processo de ensino- } \\
\text { aprendizagem de Língua } \\
\text { Portuguesa como segunda língua, na modalidade } \\
\text { escrita. }\end{array}$ \\
\hline
\end{tabular}

Fonte: A Autora (2021).

$\mathrm{Na}$ análise com foco em I projeto de extensão (quadros 02 anterior), o olhar é voltado para o projeto extensionista, o mesmo projeto onde surgiu o interesse por essa pesquisa baseado na relação entre o resumo e resultado final, onde identificamos que no 
resultado final foi alcançado conforme o previsto pelos resultados esperados no resumo. Pode-se afirmar que foi satisfatório para todos os envolvidos no processo, correspondendo exatamente ao que a creditávamos desde o início da pesquisa: a Universidade com suas ações baseadas em projetos de extensão voltados à educação de surdos e sua comunidade tem conquistado avanço perceptível. Diante dos estudos e resultados, ficou evidente que através da interferência da Universidade em contextos de extensão universitária voltada à comunidade surda conjuntamente às lutas travadas por eles, produziu muitos resultados positivos, porém muito ainda precisa ser feito para o avanço da educação de surdos.

Quadro 03 - Síntese dos projetos de extensão voltados à comunidade surda

\begin{tabular}{|c|c|c|c|}
\hline ANO & $\begin{array}{c}\text { PROJETO } \\
\end{array}$ & CAMPUS & COORDENADOR \\
\hline 2016 & $\begin{array}{c}\text { POPULARIZANDO A } \\
\text { LINGUA BRASILEIRADE SINAIS } \\
\text { NAS ESCOLAS BRAGANTINAS }\end{array}$ & BRAGANÇA/EDUCAÇÃO & $\begin{array}{c}\text { GLAUCIA } \\
\text { CAROLINE } \\
\text { SILVA } \\
\text { DE OLIVEIRA }\end{array}$ \\
\hline 2016 & $\begin{array}{c}\text { BANCO DE ATIVIDADES } \\
\text { PEDAGÓGICAS EM LÍNGUA } \\
\text { PORTUGUESA PARA ALUNOS } \\
\text { SURDOS }\end{array}$ & $\begin{array}{c}\text { TOCANTINS } \\
\text { CAMETÁ/EDUCAÇÃO }\end{array}$ & $\begin{array}{l}\text { JOSÉ } \\
\text { ORLANDO } \\
\text { FERREIRA DE } \\
\text { MIRANDA } \\
\text { JÚNIOR }\end{array}$ \\
\hline 2017 & $\begin{array}{l}\text { ACESSIBILIDADE EM LIBRAS: } \\
\text { PERCEPÇÃO SEMIÓTICA NOS } \\
\text { ESPAÇOS DA UNIVERSIDADE }\end{array}$ & $\begin{array}{c}\text { REITORIA } \\
\text { BELÉM/TECNOLOGIA E } \\
\text { PRODUÇÃO (TEMÁTICA) }\end{array}$ & $\begin{array}{c}\text { ARLETE } \\
\text { MARINHO } \\
\text { GONÇALVES }\end{array}$ \\
\hline 2017 & $\begin{array}{c}\text { DESENVOLVIMENTO DE UM } \\
\text { AMBIENTE DE APRENDIZAGEM } \\
\text { DEVOCABULÁRIO VISANDO O } \\
\text { APRENDIZ SURDO }\end{array}$ & 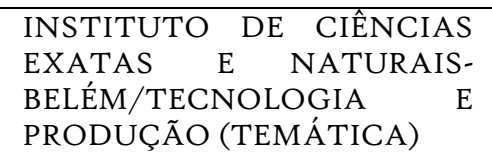 & $\begin{array}{l}\text { NELSON CRUZ } \\
\text { SAMPAIO } \\
\text { NETO }\end{array}$ \\
\hline 2017 & $\begin{array}{c}\text { ENSINO E APRENDIZAGEM DE } \\
\text { LÍNGUAS: ESTRATÉGIAS } \\
\text { METODOLÓGICAS PARA ALUNOS } \\
\text { SURDOS NAS AULAS DE LÍNGUAS } \\
\text { ADICIONAIS (LA) }\end{array}$ & CASTANHAL/EDUCAÇÃO & $\begin{array}{c}\text { RUBENS } \\
\text { ALEXANDRE } \\
\text { DEOLIVEIRA } \\
\text { FARO } \\
\end{array}$ \\
\hline 2018 & $\begin{array}{c}\text { A INCLUSÃO DO SURDO NA } \\
\text { EDUCAÇÃO DE JOVENS E } \\
\text { ADULTOS (EJA) }\end{array}$ & $\begin{array}{l}\text { INSTITUTO DE EDUCAÇÃO } \\
\text { MATEMÁTICA E } \\
\text { CIENTÍFICA/EDUCAÇÃO }\end{array}$ & $\begin{array}{l}\text { FRANCISCA } \\
\text { MARIA } \\
\text { CARVALHO }\end{array}$ \\
\hline 2018 & $\begin{array}{c}\text { LIBRAS PARA OBJETIVOS } \\
\text { ESPECÍFICOS }\end{array}$ & $\begin{array}{l}\text { INSTTITUTO DE LETRAS E } \\
\text { COMUNICAÇÃO }\end{array}$ & $\begin{array}{l}\text { ELLEN SUSAN } \\
\text { FERREIRA } \\
\text { FORMIGOSA } \\
\text { MARIEROSE }\end{array}$ \\
\hline 2018 & $\begin{array}{c}\text { CURSO DE LÍNGUA PORTUGUESA } \\
\text { PARA } \\
\text { SURDOS }\end{array}$ & $\begin{array}{l}\text { INSTITUTO DE LETRAS E } \\
\text { COMUNICAÇÃO }\end{array}$ & $\begin{array}{l}\text { EDER } \\
\text { BARBOSA } \\
\text { CRUZ }\end{array}$ \\
\hline 2019 & $\begin{array}{c}\text { PERSPECTIVAS DA INCLUSÃO DE } \\
\text { SURDOS: INCLUSÃO EM } \\
\text { PERSPECCTIVA }\end{array}$ & $\begin{array}{l}\text { CAMPUS DE TOCANTINS- } \\
\text { CAMETÁ/EDUCAÇÃO }\end{array}$ & $\begin{array}{c}\text { JOSÉ } \\
\text { ORLANDO } \\
\text { FERREIRA DE }\end{array}$ \\
\hline
\end{tabular}




\begin{tabular}{|c|c|c|c|}
\hline & & & $\begin{array}{l}\text { MIRANDA } \\
\text { JÚNIOR }\end{array}$ \\
\hline 2019 & $\begin{array}{c}\text { APRIMORAMENTO NO PROCESSO } \\
\text { DE COMUNICAÇÃO E } \\
\text { ATENDIMENTO ODONTOLÓGICO } \\
\text { PARA PACIENTES COM } \\
\text { DEFICIENNCIA AUDITIVA }\end{array}$ & $\begin{array}{l}\text { INSTITUTO DE CIÊNCIAS } \\
\text { BIOLÓGICAS/SAÚDE }\end{array}$ & $\begin{array}{l}\text { VANIA CASTRO } \\
\text { CORRÊA }\end{array}$ \\
\hline 2019 & $\begin{array}{c}\text { UM APLICATIVO } \\
\text { MULTIPLATAFORMA PARA } \\
\text { GEOLOCALIZAÇÃO DE SURDOS } \\
\text { UTILIZANDO LIBRAS } \\
\text { REGIONAIS }\end{array}$ & $\begin{array}{c}\text { INSTITUTO DE } \\
\text { CIÊNCIAS EXATAS E } \\
\text { NATURAIS/TECNOLOGI } \\
\text { A E PRODUÇÃO }\end{array}$ & $\begin{array}{l}\text { MARCELLE } \\
\text { PEREIRAMOTA }\end{array}$ \\
\hline 2019 & $\begin{array}{l}\text { OFICINA DE LEITURA E ESCRITA } \\
\text { DE PORTUGUÊS PARA SURDOS } \\
\text { (OLEPS) }\end{array}$ & $\begin{array}{c}\text { INSTITUTO DE LETRAS E } \\
\text { COMUNICAÇÃO/EDUCAÇÃO }\end{array}$ & $\begin{array}{l}\text { WALDEMAR } \\
\text { DOS SANTOS } \\
\text { CARDOSO } \\
\text { JUNIOR }\end{array}$ \\
\hline
\end{tabular}

Quadro 03 - Síntese dos projetos de extensão voltados à comunidade surda

(conclusão)

\begin{tabular}{|c|c|c|c|}
\hline ANO & $\begin{array}{l}\text { PROJETO } \\
\end{array}$ & CAMPUS & COORDENADOR \\
\hline 2020 & $\begin{array}{c}\text { CIÊNCIAS COM AS } \\
\text { MÃOS: OS DESAFIOS DOS } \\
\text { NOVOS PROFESSORES } \\
\text { DIANTE DO ALUNO } \\
\text { SURDO }\end{array}$ & $\begin{array}{c}\text { INSTITUTO DE CIÊNCIAS } \\
\text { EXATAS E } \\
\text { NATURAIS/EDUCAÇÃO }\end{array}$ & $\begin{array}{l}\text { GUNAR VINGRE } \\
\text { DASILVA } \\
\text { MOTA }\end{array}$ \\
\hline 2020 & $\begin{array}{c}\text { CAMPUS DIGITAL } \\
\text { INCLUSIVO: GLOSSÁRIO } \\
\text { DE TERMOS TÉCNICOSEM } \\
\text { LIBRAS PARA OS CURSOS } \\
\text { DE } \\
\text { GRADUAÇÃO DO } \\
\text { CAMPUS DE } \\
\text { CASTANHAL }\end{array}$ & CASTANHAL/COMUNICAÇÃO & $\begin{array}{c}\text { TIAGO } \\
\text { AUGUSTO } \\
\text { NASCIMENTO } \\
\text { RODRIGUES }\end{array}$ \\
\hline 2020 & $\begin{array}{c}\text { LIBRAS NA } \\
\text { COMUNIDADE }\end{array}$ & ABAETETUBA/EDUCAÇÃO & $\begin{array}{c}\text { MARIA } \\
\text { MADALENA } \\
\text { SILVA DA SILVA }\end{array}$ \\
\hline 2020 & $\begin{array}{l}\text { VOZES E MÃOS QUE } \\
\text { CANTAM: } \\
\text { POESIA E } \\
\text { MÚSICA }\end{array}$ & BRAGANÇA/EDUCAÇÃO & $\begin{array}{c}\text { ALESSANDRA } \\
\text { FABRICIA CONDE } \\
\text { DASILVA }\end{array}$ \\
\hline 2021 & $\begin{array}{l}\text { CAMPUS DIGITAL } \\
\text { INCLUSIVO: GLOSSÁRIO } \\
\text { DE TERMOS TÉCNICOSEM } \\
\text { LIBRAS PARA OS CURSOS } \\
\text { DE GRADUAÇÃO DO } \\
\text { CAMPUS DE CASTANHAL }\end{array}$ & CASTANHAL/COMUNICAÇÃO & $\begin{array}{c}\text { TIAGO } \\
\text { AUGUSTO } \\
\text { NASCIMENTO } \\
\text { RODRIGUES }\end{array}$ \\
\hline 2021 & $\begin{array}{l}\text { CURSO DE LÍNGUA } \\
\text { PORTUGUESA } \\
\text { PARA SURDOS }\end{array}$ & $\begin{array}{c}\text { INSTITUTO DE } \\
\text { EDUCAÇÃOMATEMÁTICA } \\
\text { E CIENTÍFICA/EDUCAÇÃO }\end{array}$ & $\begin{array}{l}\text { FRANCISCA } \\
\text { MARIA } \\
\text { CARVALHO }\end{array}$ \\
\hline 2021 & $\begin{array}{c}\text { SINALÁRIO DE LIBRAS: } \\
\text { DOCUMENTANDO A } \\
\text { LÍNGUA DESINAIS EM } \\
\text { CONTEXTOS } \\
\text { ESPECIALIZADOS }\end{array}$ & REITORIA/EDUCAÇÃO & $\begin{array}{l}\text { DENISE COSTA } \\
\text { MARTINELLI }\end{array}$ \\
\hline
\end{tabular}


Fonte: A Autora (2021)

No quadro 03 anterior está agrupado a síntese dos projetos de extensão voltados à comunidade surda entre os anos de 2016 a 2021 relacionado ao campus em que foi desenvolvidoo projeto e ao coordenador. Partindo dessa síntese, evidencia-se o centro deste estudo e permite avaliar as novas análises que deram importantes significados para o desenvolvimento do corpus. Nessa perspectiva, foi possível constatar as temáticas, as problemáticas, a fundamentação teórica, os objetivos esperados e alcançados ou não pelos dados coletados como pré-requisito para verificação de hipóteses até se chegar ao que foi proposto nesta pesquisa: verificar as contribuições dos projetos de extensão para a comunidade surda.

\section{CONSIDERAÇÕES FINAIS}

Quando se iniciou este estudo de pesquisa, constatou-se que muito se discute sobre projetos de extensão, no entanto, pouco é discutido sobre suas ações, de que forma são aplicadas e quais seus resultados, diante dessa dificuldade de informações, pensou-se em investigar sobreExtensão Universitária para a comunidade surda.

Desse modo, a pesquisa teve como objetivo geral verificar as contribuições da extensão universitária para a comunidade surda, constatando que esse objetivo geral foi atendido ao conseguir demonstrar as contribuições positivas da extensão universitária para a comunidade surda. Especificamente, objetivou-se identificar as estratégias utilizadas pelos projetos de extensão da Universidade Federal do Pará na integração com a comunidade surda; analisar ações da extensão universitária para a comunidade surda em várias temáticas: EDUCAÇÃO, SAÚDE, COMUNICAÇÃO, TECNOLOGIA E PRODUÇÃO. Nelas todas foram possíveis verificar as estratégias utilizadas pelos projetos, conseguindo, também, descobrir as ações desses projetos de extensão nas temáticas destacadas. Dessa forma, as metas estabelecidas foram atendidas.

A pesquisa partiu da pergunta: de que maneira a extensão universitária contribui para a comunidade surda? Tendo como hipótese que as ações realizadas nos projetos de extensão contribuem na inclusão da comunidade surda no mundo contemporâneo. Pode-se dizer que confirmamos a hipótese, tendo respondido todas as questões.

Dada a metodologia proposta, tivemos algumas limitações como a análise de um número pequeno de relatórios comparado à possibilidade de que o trabalho poderia ter sido 
mais amplo e preciso, caso tivéssemos tido o retorno de todos a quem foi solicitado colaboraçãono que se refere à coleta dos relatórios finais e, frente ao momento de pandemia em que estamos passando, não podendo ir até a Universidade coletar os dados dos relatórios.

Entretanto, o estudo foi muito satisfatório e de grande valia para uma possível continuação a quem se interessar em pesquisar sobre o tema, ressaltando a importância de entrevistar alunos surdos participantes de projetos de extensão, de ter acesso aos projetos completos que se encontram na Universidade Federal do Pará, pois neles estarão qualquer informação necessária para tornar o trabalho mais completo, uma vez que um artigo não permiteexpandir tanto devido ao seu tamanho limitado.

Este estudo afirma o que de certa forma já esperávamos: um projeto de extensão é um instrumento de grande valor para o avanço de uma sociedade mais justa e igualitária, na educação de surdos e para a comunidade surda, o qual se torna uma gama de oportunidades para o desenvolvimento como pessoas cidadãs e autônomas, além de formar profissionais capacitados para o mundo da educação.

\section{REFERÊNCIAS}

ARROYO, D.M.P.; ROCHA, M.S.P.M.L. Meta-avaliação de uma extensão universitária:estudo de caso. Avaliação, v.15, n.2, p.13I-I57, 2010.

BRASIL. Artigo 22 do Decreto $\mathrm{n}-5.626$ de 22 de Dezembro de 2005. Art. 22 do Decreto5626/o5 (jusbrasil.com.br). Acesso em: I2 agosto.2021.

BRASIL. Lei Federal 10.436 de 24 de abril de 2002. Dispõe sobre a Língua Brasileira de Sinais - Libras e dá outras providências.

BRASIL. Decreto 5.626 de 22 de dezembro de 2005. Regulamenta a Lei noio.436, de 24deabril de 2002, que dispõe sobre a Língua Brasileira de Sinais - Libras, e o art. I8 da Lei noro.098, de i9 de dezembro de 2000.

BEHARES, L. E. Que es uns seña? Trabajo preentado em el primer encuentro de educadoressordos. Ministério de Educación: Venezuela, 1987.

CASSIANO, Paulo Victor. O surdo e seus direitos: os dispositivos da lei 10.436 e do decreto 5.626. Revista virtual de cultura surda, v. 21, n. I, p. I-28, 2017.

CASTRO, L. M. C. A universidade, a extensão universitária e a produção de conhecimentos emancipadores: ainda existem utopias realistas. UFB: Rio de Janeiro, 2004. 
CHAVES, M.; GAMBOA, S. S. Prática de ensino: formação profissional e emancipação.Maceió: EDVFAL, 2000.

DE PAULA, L.S.B.CULTURA ESCOLAR, CULTURA SURDA E CONSTRUÇÃO DE IDENTIDADES NA ESCOLA, Rev. Bras. Ed. Esp., Marília, v.15, n.3, p.407-416, Set.-Dez.,2009.pág.412.

GIL, A. C. Métodos e técnicas de pesquisa social. 5. ed. São Paulo: Atlas, I999.

LÓPEZ MELERO, M. La escuela inclusiva: una oportunidad para humanizarnos.

Revista Interuniversitaria de Formación del Profesorado Site externo, vol. 26, núm.2, agosto, 2012, pp. 143 à 145. Universidad de Zaragoza. Zaragoza, España.

MONTEIRO, Myrna Salerno. Mestres e Doutores Surdos: Sobre a Crescente FormaçãoEspecializada de Pessoas Surdas no Brasil Site externo. Centro Virtual de Cultura Surda. Revista Virtual de Cultura Surda. Edição no 23, maio de 2018.

NOGUEIRA, M. das D. P. (Org.). Extensão universitária: diretrizes conceituais e políticas. Belo Horizonte: PROEX/UFMG; O Fórum, 2000. http://proex.ufsc.br/files/2016/o4/Política-Nacional-de-Extensão-Universitária-ebook.pdf. Acesso em: io. Setembro. 2021.

UERGS. Anexo 1o - classificações das ações e extensão universitárias. 2017.

Disponível em: https://uergs.edu.br/upload/arquivos/201702/o9101436-anexo-10classificacao-das-acoes-de-extensao-universitarias.pdf Acesso em 20 set. 202I às 00:48.

PLANO NACIONAL DE EXTENSÃO UNIVERSITÁRIA. Fórum de PróReitores de Extensão das Universidades Públicas Brasileiras e SESu/ MEC. Edição Atualizada,2000/2001.

PROEX | Home (ufpa.br). Acesso em: 20 julho.202I.

SÁ, N. R. L. de. Cultura, Poder e Educação de Surdos. Manaus: Editora da UniversidadeFederal do Amazonas,2002.

SÁ, N. R. L. de. Cultura, poder e educação de surdos. - 2.ed. São Paulo: Paulinas,2oro.

SANCHEZ, C.M. La educación de los sordos en un modelo bilíngüe Mérida: Ickonia, I99I.

Santos, José Luiz dos, o que é cultura, São Paulo : Brasiliense, 2006. - - (Coleção primeiros passos ; iıo. Pág.7).

SISAE (ufpa.br). Acesso em: 2I julho.2021

SLOMSKI, V. G. Educação Bilíngue para surdos: concepções e implicações práticas. Curitiba: Juruá, 2010.

SKLIAR, Carlos. A surdez um olhar sobre as diferenças. 6. ed. Porto Alegre: Mediação,2013. 